\title{
JUDIOS Y CRISTIANOS: LA APOLOGÉTICA DE LA TOLERANCIA EN EL «LLIBRE DEL GENTIL»
}

\author{
Sebastià Trías Mercant \\ Palma de Mallorca
}

\section{RESUMEN}

Para entender la apologética Iuliana de la tolerancia debemos situar el Llibre del gentil (1274/76) en el contexto de la Mallorca de las tres religiones, de las disputas judeo-cristianas, de los sectarismos judíos y musulmanes y del cisma y heterodoxias cristianas. A partir de ahí se estudian los conceptos de «tolerancia de benevolencia» y de «tolerancia racional» en la apologética de Llull. Esta no pretende cambiar una creencia por otra, sino tender el puente de la tolerancia racional para comprender la verdad de la fe, buscando la utopía de la unidad religiosa. Se trata de buscar solución al conflicto judeo-cristiano del mesianismo, por ejemplo, buscando un acercamiento a través del común concepto de esperanza, respetando las diferencias semánticas de uno y otro pensamiento.

Palabras clave: Tolerancia, apologética, racional, combinatoria, creencia

\section{ABSTRACT}

In order to understand Llullian apologetics of tolerance we must situate the Llibre del gentil (1274/76) within the context of the Mallorca of the three religions, that of the Judeo-Christian disputes, of the JudeoMuslim sectarisms, of the schism and of the Christian heterodoxies. Only by taking all this into account, can we study in Llullian apologetics concepts such as «tolerance of benevolence» or «rational tolerance».

Llullian apologetics doesn't try to change a belief by another but to lay the bridge of rational tolerance to understand the truth of faith in the search of the utopia of religious unity. The aim would be therefore, to look for a solution to the Judeo Christian conflict of messianism, by means, for example, of a rapprochement through the common concept of hope, even though respecting the semantic differences of both systems of thought.

Key words: Tolerance, apologetics, rational, combinatory, credence.

\section{EL CONTEXTO PLURIIDEOLÓGICO}

Jordi Llimona, en un reciente libro, ${ }^{1}$ ha subrayado un sentido negativo y un significado positivo del concepto «tolerancia». En el primer caso; tolerancia significa soportar indulgentemente en

1 Llimona, Jordi, La tolerància i els seus fonaments; Barcelona, Edicions 62, 1997. 
los otros algo que se desaprueba. En su sentido positivo, en cambio, la tolerancia exige que el otro pueda desplegar sin trabas su alteridad desde el respeto a su persona, a su pensamiento y a sus acciones.

La tolerancia implica, pues, un proyecto marcado por la pluralidad y ajeno tanto a todo pensamiento débil, que conduciría a la dimisión de responsabilidades, como a cualquier pensamiento integrista, nutricio de todos los fundamentalismos que absolutizan los dogmas.

¿Cuál es la semántica del Llibre del gentil e dels tres savis (1274-76) de Ramon Llull dentro de ese esquema epistemológico de la tolerancia?

Para contestar la pregunta debemos situar el Llibre del gentil en el contexto de «la Mallorca de las tres religiones», ${ }^{2}$ de las disputas judeo-cristianas, así como de los sectarismos judíos y musulmanes y del cisma y heterodoxias cristianas. ${ }^{3}$

Eusebi Colomer ya dejó claro que la relación entre cristianismo y judaísmo en el marco histórico de la Edad Media se caracterizaba por tres notas fundamentales: ${ }^{4}$

Primera: La actitud de tolerancia de los cristianos respecto de los judíos es inversamente proporcional al paso del tiempo.

A medida que se consolida el cristianismo pierde eficacia el judaísmo, teniendo éste que enfrentarse, a partir del siglo XIII, a un nacionalismo cristiano cada vez más fuerte. La protección e, incluso, el mimo que tenían las juderías en los territorios recién conquistados, como lo demuestran los Repartiments de Jaime I de Aragón, se deterioran paulatinamente hasta acabar en una situación insoportable a comienzos del siglo XV a causa de la Pragmática de Valladolid (1412) y de la Bula de Benedicto XIII, ratificada por Eugenio IV (1434). Esta situación se agravó por la acción de los «estatutos de sangre» entre los judíos conversos.

Segunda: La tolerancia respecto de los judíos tuvo un carácter político, ya que era una necesidad para la convivencia de las tres religiones en un mismo pueblo. ${ }^{5}$ Por ejemplo, las leyes leonesas de 1020 disponen la constitución de comisiones arbitrales para resolver los problemas de propiedad entre judíos y cristianos y los caballeros de Toledo defienden en 1212 a sus conciudadanos judíos contra las represalias de los cruzados ultrapirenaicos.

Tercera: La situación ambivalente de los judíos dentro de la sociedad hispana. Por una parte, su importante colaboración en las empresas culturales cristianas. Por otra, su posición cada vez más desfavorable en las polémicas religiosas y en la literatura de controversia. Los hermanos Carreras Artau han hecho coincidir esta ambivalencia con una doble configuración geogràfica. Mientras Castilla - dicen-, más próxima a los pueblos orientales, es mayormente atraída por la cultura judía, Cataluña, más abierta al occidente europeo, importa las controversias antijudías. ${ }^{6}$

2 Trías Mercant, Sebastià, Història del pensament a Mallorca, Mallorca, Ed. Moll, 1985, vol I, pp. 17-59. Soto, Ricardo, «La aljama judaica de Ciutat en el siglo XIII (época de Jaime I»), Boletín Sociedad Arqueológica Luliana, (1978) pp. $145-184$.

3 Garcias Palou, Sebastián, Ramon Lull en la historia del ecumenismo, Barcelona, Herder, 1986. Ramis, Pedro, Lectura del «Liber de civitate mundi» de Ramon Llull, Barcelona, PPU, 1992.

• 4 Colomer, Eusebi. «Ramon Llull y el judaismo en el marco histórico de la Edad Media Hispana» en Estudios Lulianos, X (1966), pp. 5-45 y XII (1968), pp. 131-144.

5 Cacigas, I. de las, Minorías étnico-religiosas de la Edad Media, 4 vols., Madrid, 1947-49.

6 Carreras Artau, Tomás y Joaquín, Historia de la filosofia española. Filosofia cristiana de los siglos XIII al XV. 2 vols., Madrid, Real Academia de Ciencias Exactas, Físicas y Naturales, 1939 y 1943. 
Estos hechos socio-políticos y religioso-culturales favorecieron una literatura apologética que tuvo sus altibajos respecto de cada una de las tres religiones medievales a lo largo del tiempo. Armand Llinarés, después de analizar una serie de obras de los siglos XI, XII y XIII, establece un corte radical entre aquellas en que aparecen ciertas «tentativas de diálogo» y las que manifiestan una evidente «hostilidad» contra los judíos y musulmanes. ${ }^{7}$ Sin embargo, si, en vez de atender sólo a escritos singulares, analizamos la obra entera de un autor, este corte se difumina porque los libros concretos dan paso a la consideración de actitudes globales e, incluso, a tendencias definidas. En este sentido, tanto la actitud rigorista basada en autoridades como la postura dialogante fundada en razones difícilmente pueden aceptarse en su radicalidad. El análisis de la obra concreta de los distintos autores demuestra que el concepto de tolerancia va desde una captatio benevolentiae del otro ${ }^{8}$ hasta la controversia pura y dura con el adversario dogmático, ${ }^{9}$ pasando por el abandono de la propia opinión cuando ésta viene castigada por razones en contra ${ }^{10}$ o por la aceptación de opiniones diversas contrastadas racionalmente. ${ }^{11}$

Es evidente que el Capistrum judaeorum (1267) y el Pugio fidei (1278) de Ramon Martí, modelo de muchas obras antijudías, son un claro ejemplo de la disputa basada en autoridades, minusvalorando el recurso a la especulación. El Kitab Miftah al-Din (1309), cuyo autor describe su participación en una polémica con un monje cristiano, buen conocedor de los textos del islam, sigue también la misma línea del dominico catalán, aunque dentro de un ambiente más popular. Sin embargo, Martí, pese a su integrismo, aparece más condescendiente a aceptar la tesis tomasiana de la especulación respecto de los praeambula fidei, ${ }^{12}$ así como el Kitab no tiene reparos en introducir experiencias y emociones personales que rebajan, en cierta manera, el rigorismo dogmático. ${ }^{13}$

Desde la perspectiva opuesta, La Disputatio sarraceni et Samuelis iudei, por ejemplo aunque muy lejos de las «razones necesarias» lulianas, se sitúa en un ambiente de cierta tolerancia, pese a fundamentarse en la autoridad del Corán y de la Biblia. ${ }^{14}$

7 Llinares, Armand, «Introduction», en Raymond Lulle, Le livre du gentil et des trois sages, París, Les editions du Cerf, 1993, pp.33-38.

8 Watts, Pauline, in Nicholas of Cusa. In Search of Godand Wisdom. Essays in Honor of Morimichi Watanabe by the American Cusanus Society, Leiden:Brill, G. Christianson, T.M. Izbicki, «Studies in the History of Christian Thought», 1991, pp. 203-218.

9 Colomer,Eusebi, «La controversia islamo-judeo-cristiana en la obra apologética de Ramón Martí» en Diálogo filosófico-religioso entre cristianismo, judaismo e islamismo durante la Edad Media en la península ibérica, Turnhout, Brepols, (1994), pp. 229-257.

10 Tomás de Aquino escribe en su Summa Theologica: Ille autem qui in suo sensu perseverat, rigidus el durus per similitudinem vocatur, III, Supp., q. 1, a.1, resp.

11 Colomer, Eusebi, «Raimund Lulls Stellung zuden Andersgläubigen:Zwischen Zwieund Streitgespräch», en Religionsgespráche im Mittelalter, 4 (1992), pp. 229-257.

12 Colomer. La controversia...

13 Koningsveldt, P.S. y Wiegers, G.A., Al-Qantara. Revista de Estudios Arabes, 15 (1994), pp. 163-199. El manuscrito original del Kitab se conserva en Argel y aparecen en distintas bibliotecas de Madrid cinco versiones aljamiadas.

14 Reinhardt, Klaus, «Un musulmán y un judío prueban la verdad de la fe cristiana: la disputa entre Abutalib y Samuel de Toledo» en Diálogo filosófico-religioso entre cristianismo, judaismo e islamismo durante la Edad Media en la península ibérica, Turnhout, Brepols, (1994), pp. 191-212. 


\section{LA POSTURA APOLOGÉTICA DE RAMON LLULL EN EL MARCO DE LAS DISPUTAS JUDEO-CRISTIANAS}

La disputa de Barcelona, ordenada por el rey Jaime I a instancias de Ramon de Penyafort, pretende determinar las diferencias conceptuales entre judíos y cristianos sobre el mesianismo, argumentando su carácter cristológico el segundo y negándolo el primero. En realidad, la disputa quedó en tablas y el rey dispuso la creación de una comisión teológica para examinar los libros rabínicos. La sentencia final no fue condenatoria en ningún aspecto, sino simplemente expurgatoria de aquellos pasajes de los textos judíos que contenían - decía- blasfemias contra el cristianismo. ${ }^{15}$

La disputa de Tortosa, que entre su preparación y conclusión duró tres largos años, planteó otra vez el tema del mesianismo, un mesías judío como libertador terrenal y político y un mesías cristiano como redentor espiritual encarnado en la persona de Cristo. La polémica fue en esta ocasión desfavorable a los judíos, ya que, a medida que avanzaba la disputa, aumentaban las conversiones de los judíos al cristianismo. El desaliento provocado por la disputa entre los círculos judíos populares estuvo alentado además por una política de presión e intolerancia contra ellos. ${ }^{16}$

El carácter más tolerante de la disputa de Barcelona y la postura más intransigente y antijudía de la de Tortosa aparece, según Llinarés, en el discurso de las distintas obras apologéticas lulianas. Llinarés, una vez fijado el «criterio de ruptura» entre obras dialogantes y obras de hostilidad, según hemos advertido anteriormente, lo aplica a la apologética luliana y descubre una «inflexión» del pensamiento de Llull, que va del «irenismo» del Llibre del gentil a la «polémica» de las obras posteriores, inflexión que se agranda y se convierte en una «fosa profunda» al redactar el Tractatus de acquisitione Terrae Sanctae (1309). ${ }^{17}$

Los lulistas suelen aceptar dicha inflexión y las diferencias que puedan existir entre ellos se reducen a una cuestión de fechas. Urvoy, por ejemplo, al dibujar la figura de un Llull christianus arabicus, subraya que en el filósofo mallorquín hay una evolución de su pensamiento y de sus actitudes y, aunque no concreta fecha, se refiere al: Liber de fine (1305) como ejemplo evidente del nuevo posicionamiento luliano. ${ }^{18}$ Colomer matiza aspectos y obras, distinguiendo entre escritos dialogantes, como el Llibre del gentil (1274-6) y, quizás también el Liber de Sancto Spiritu (1274), libros apologéticos, como el Liber Tartari et Christiani (1285?) y el Liber de quinque sapientibus (1295?), y obras polémicas como la Disputatio Raymundi christiani et Hamar sarraceni (1308). ${ }^{19}$

Sin embargo, el propio Llull parece no aceptar rupturas en su pensamiento apologético, entre el Llibre del gentil y sus obras posteriores. Escribe en el Llibre de meravelles (1288-89):

En la disputació de tots tres fo ordenat en quina manera fos al gentil significada veritat e falsetat, per ço que lo gentil prengués veritat e que leixàs falsetat. L'ordonament fo eital, ço és

15 Valls Taberner, Ferran, «San Ramon de Penyafort», en Obras Selectas, Madrid-Barcelona, 1953, I, pp. 321 y ss.

16 Véase la polémica desde la perspectiva de ambós contendientes en Pacios, A., La disputa de Tortosa, 2 vols., Madrid, 1957. Baer, F., Die Juden in Christlichen Spanien, 2 vols., Belín, 1929-30 y segunda edición inglesa, A History of the Jewes in Christian Spain, Filadelfia, 1961-62, II, pp. 410-449.

17 Llinares, Armand, «Introduction», en Raymond Lulle, o.c., pp. 39 y 44.

18 Urvoy, Dominique, «La idea de Christianus arabicus» en Al-Quantara. Revista de Estudios Arabes, XV (1994), pp. 497-507.

19 Colomer, Raimund Lulls Stellung... 
a saber: que aquella lig que ab les dignitats de Déu e ab vertuts creades hauria major concordança, e qui als vicis seria pus contraria, convenia esser vera, e les altres, contraries a ella, convenien esser falses [...]. Disputant per aital ordonament, provà lo crestià esser sa lig en veritat, e totes les altres esser en falsetat, segons que és provat en lo Libre de gentil. ${ }^{20}$

¿Existe, pues, una discordancia entre la hermenéutica lulista y la relectura que hace Llull de su Llibre del gentil en obras posteriores?

Llinarés parece aceptarla al indicar que la «apreciación de Llull no coincide con la nuestra» ya que el LLibre del gentil «tampoco es lo que parece ser todavía para nosostros». ${ }^{21}$

Bonnner, en cambio, se limita a señalar que Llull aquí asevera categóricamente una cosa que daba la impresión de haber dejado al aire en el Libro del gentil; o sea el hecho de que el cristiano hubiera convencido al gentil de la verdad de su fe y de la falsedad del judaísmo y del islam. ${ }^{22}$

Guillem Colom parte de la idea de un proselitismo luliano radical y, por tanto, no admite rupturas, porque no acepta el espíritu de tolerancia que algunos ven en el epílogo del LLibre del gentil. Reconocerlo equivaldría - dice - a aprobar una franca contradicción con el ardiente proselitismo de Llull y, además, insinuar un incomprensible sincretismo de las tres religiones monoteístas. ${ }^{23}$ En todo caso podría pensarse en un «ingenuo artificio» del autor, con el fin de reservar a los lectores la posibilidad de cuestionar y preguntarse que creencia pudo escoger el gentil para ser más agradable a Dios. $^{24}$

Otros autores, sin embargo, no consideran contradictoria la actitud de tolerancia interreligiosa con la defensa de la verdad cristiana, puesto que Llull pudo reconocer implícitamente que, en cualquier conversión, es necesaria, para completar los argumentos de razón en la teología cristiana, la gracia $^{25}$ o pudo hacer valer su fuerte espíritu ecumenista. ${ }^{26}$

\section{LOS CONCEPTOS DE TOLERANCIA DE BENEVOLENCIA Y DE TOLERANCIA RACIONAL}

Verdaderamente causa sorpresa a un lector actual del Libre del gentil que el autor manifieste una connivencia tan exquisita de las tres religiones - honra muy escrupulosamente la antigüedad

20 «En la disputa de todos los tres sabios se acordó de qué manera sería significada al gentil la verdad y la falsedad, con el fin de que el gentil tomara la verdad y dejara la falsedad. El acuerdo fue éste, a saber: Que la ley más acorde con las dignidades de Dios y las virtudes creadas y más opuesta a los vicios sería la verdadera, y que las otras, contrarias a ella, serian falsas [...]. Discutiendo de esta manera, el cristiano probó que su lèy era verdadera y todas las otras falsas, según aparece en el Libre del gentil». Llull, Ramon, Fèlix, Lib. VIII, cap. LXXIX., en Bonner, Antoni, Obres Selectes de Ramon Llull, Palma de Mallorca, ed. Moll, 1989.

21 Llinares, o.c., pp. 40 y 41.

22 Bonner, o.c., vol. II, nota 144, p. 259 y vol I, nota 4, p. 269.

23 Colom, Guillem, «Ramón Llull y los orígenes de la literatura catalana» en Estudios Lulianos, XIII (1969) pp. 133-151.

24 Obrador, Mateu, «Introducció», en Rossello, Gerónimo, Obras de Ramón LLull, Palma, Imp. de P. Gelabert, 1901-3, 3 vols., I, XXXIX

25 Hillgarth, Jocelin, Ramon Lull and Lullism in Fourteenth-Century France, Oxford, 1971.

26 Matas, D., La doctrina teológica de Ramón Llull en el "Libre del gentil e dels tres savis», Tesis doctoral, Universidad de Barcelona, s/f, p. 45. 
jerárquica de las tres religiones, dando, por ello, primacía al judaísmo; el sabio cristiano está dispuesto a ceder la palabra a los otros; el gentil no acepta explicaciones del cristiano ni del musulmán respecto de aquellos puntos que ya fueron tratados por el judío y, sobre todo, en el «epílogo», los tres sabios no desean conocer la decisión del gentil, cosa que privilegiaría una religión sobre las otras, y se piden mutuamente perdón por si han dicho contra la religión del otro nulla vilana paraula-y años más tarde afirme que el cristiano ya demostró en ese libro la verdad de su religión y la falsedad de las otras dos.

La sorpresa puede desvanecerse al analizar el concepto de tolerancia. León Poliakov se refiere a la «extraordinaria tolerancia» en que vivía aquella comunidad española medieval, que tenía por Dios el «Dios común de Abvaham y padre común de los tres pueblos». Para Poliakov esa extraordinaria tolerancia - nos referimos ahora y aquí a las relaciones entre judíos y cristianos-, pese a que oficialmente cada culto estaba protegido y reglamentado por el poder, comportaba, por una parte, un «fraterno entendimiento» social respecto a la vida política, a la vida íntima y al dominio de la vida religiosa comunitarias y, por otra, la confluencia en un mismo «racionalismo grecoárabe» y en una «mística popular». ${ }^{27}$

Ramon Llull está muy cerca de esa doble dimensión de la tolerancia. En esta misma línea, el Llibre del gentil rezuma una tolerancia de benevolencia, actitud sociológica de respeto y comprensión del otro, y una tolerancia racional como exigencia por fijar unas condiciones racionales del discurso religioso.

Podemos encontrar diferencias entre la exquisitez de trato entre unas y otras religiones en el Llibre del gentil y la actitud adoptada por Llull en sus obras posteriores. No obstante, está claro que no existe aquella «fosa profunda» que señalaba Llinarés, ya que Llull no renuncia jamás a la tolerancia convivencial de las tres religiones. Los textos lulianos son numerosos; sin embargo para muestra basta un botón:

En 1285 Llull dice que los judíos con su cautividad son merecedores de mayor mérito que los mususlmanes y que los cristianos con su libertad, ya que aquella es una prueba de que, Deus propter hoc diligat nos, quia sustinet nos. ${ }^{28}$

Cinco años después, en 1290, en el Tractatus de modo convertendi infideles, añade que no es bueno «hacer la guerra (a los infieles) atravesándolos con nuestra espada y arrebatándoles sus tierras». Es mejor «convertirlos y dejarles lo que poseen» para que de esa manera «seamos artífices de la concordancia y del amor». ${ }^{29}$

Mucho más conciliador —una especie de atrevimiento suicida - es todavía Llull en el Libre de coneixença de Déu (1300), ya que, con el fin de no agraviar ni ofender a los judíos y sarracenos, es capaz de hablar muy veladamente de las Divinas Personas. En el prólogo del libro escribe con cierto riesgo: Se oculta en las páginas que siguen el tema de la Trinidad para que:

27 Poliakov, León, Historia del antisemitismo. De Mahoma a los marranos, Barcelona, Muchnik editores, 1980, pp. $133-138$ y $152-154$.

28 Llull, Ramon, Liber Tartari et Crhistiani, ed. Maguntina, 1721-42, IV, 2a-b.

29 Sugranyes De Franch, Ramon, Traité sur la maniere de convertir les infidèles, Trad. y edic. SchöneckBeckenried, 1954, p. 140. 
los jueus e los sarrahins no sien agreujats en aquest libre a legir e oir, con sia açò que ells hajen greuje de oir parlar de la divina trinitat de Deu. ${ }^{30}$

Si no existe un corte radical entre el Llibre del gentil y las posteriores obras polémicas respecto a la tolerancia de bẹnevolencia, mucha más continuidad se da entre ambos grupos respecto de la tolerancia racional.

En el Llibre del gentil el musulmán pretende probar el carácter divino del Corán por la posesión islámica de Jerüsalén, la ciudad de los antiguos profetas del judaísmo y la ciudad santa del cristianismo. Si el Corán —argumenta el musulmán — no fuera la palabra de Dios, el poder y la justicia divina se opondrían a la justicia de los cristianos y de los judíos, cosa imposible porque contradiría el castigo que cae sobre ellos de no poseer Jerusalén a causa de no creer en lo que dice el Corán. ${ }^{31}$

Llull en el Liber de fine, uno de sus libros más radicales, responde en cierta medida al duro argumento musulmán, al conjugar los conceptos de bellator rex y de scientes praedicantes. El objetivo primario del «rey batallador» es la recuperación de la ciudad de Jerusalén. Pero esa recuperación sería vana sin una conversión ideológica, conversión encomendada a los «sabios predicadores», cuya misión no es imponer las creencias religiosas mediante autoridades, sino demostrarlas por «razones necesarias».

Llull, refiriéndose a los judíos, escribe que las auctoritates reducant ad necessarias rationes. $\mathrm{Y}$ añade a continuación: «Et idea esset bonum, quod illi sapients in haebraico sic studentes multas colligeret auctoritates et ipsas ad necessarias rationes applicarent». No contento con ello, Llull remite a su propio modelo de aplicación tal como lo desarrollan las «artes especiales» del Liber de syllogismis, del Liber de significatione y del Liber de actibus divinarum dignitatum. ${ }^{32}$

Mucho más concreto es todavía al declarar la voluntad del rey de Túnez de abandonar el islamismo y aceptar el cristianismo, siempre que se le probara la verdad de la fe cristiana. Pero, ante la respuesta de uno de los muchos «predicadores ignorantes», para quien christianorum fides non erat probabilis, sed tantum credibilis, el rey musulmán responde que nolebat credere pro credere dimitterea, sed bene dimittere credere pro intelligere veritatem. ${ }^{33}$

Para sustituir el credere pro intelligere veritatem, Llull se refiere en el Liber de fine a la exaltatio humani intellectus y en el Llibre del gentil a la «dama Inteligencia». Se trata en ambos casos de enseñar la fe mediante razones. Y enseñar la fe mediante razones supone construir un discurso, que LLull califica de novella manera de disputació, ${ }^{34}$ para razonar las distintas creencias con la posibilidad de llegar a un acuerdo.

30 Para que «los judíos y sarracenos no sean agraviados en este libro al leer y oir aquello de lo que sientan agravio cuando oyen hablar de la divina trinidad de Dios». Obras de Ramon Llull, edc. Jerónimo Rosselló, 1-3, Palma de Mallorca, 1901-1903, vol. 2 (1901), p. 376.

31 Llull, Ramon, Llibre del gentil e dels tres savis, Norl, Palma de Mallorca, Patronat Ramon Llull, 1983, pp. 167-168.

32 Llull, Ramon, Liber de fine, ed. facsímil de la de 1665, Colegio de la Sapiencia, Petra (Mallorca), Imp. Apóstol y Civilizador, 1986, p. 26.

33 Llull, Idem, p. 53. La misma fórmula aparece en el Liber de demostratione per aequiparantiam, ed. Maguntina, 1721-1742, IV, prólogus, 2b-3a y en el Fèlix de les meravelles del mon, ed. Rosselló, 1.2. (1903), 1, p. 83.

34 Llull, Llibre del gentil, Norl., p. 158. 
LLull piensa que los scientes praedicantes deben dominar el «Arte» - «generalis», en cuanto se fundamenta en principios y reglas universales; «compendiosa», porque puede resumirse en lo fundamental; «inventiva», ya que permite descubrir discursivamente la verdad, y «demostrativa», en la medida que llega a conclusiones- y saber aplicarla mediante el Liber de praedicatione, el Liber de concilio y el Liber de gentili, ${ }^{35}$ libro que más adelante califica como Arbor gentilis y define como:

ars, eo quia divina intelligentia cum suis arboribus docet artificialiter invenire [...]; et dicitur specialis, quia ad hoc principia specialissima sunt deducta. ${ }^{36}$

Confirmada la presencia epistemológica del Llibre del gentil en el Liber de fine podemos afirmar la continuidad metodológica de Llull respecto de la relación entre religiones y preguntarnos a la vez por la tolerancia racional de dicha metodología.

El criterio de la tolerancia racional en el Llibre del gentil permite sentar las condiciones para la racionalidad de las creencias religiosas que había sido descartada en virtud de las restricciones impuestas por el criterio de autoridad dogmática. Escribe Llull en el prólogo del libro:

E pus per auctoritats no'ns podem avenir, que asajasem si'ns puriem avenir per rahons demostratives o necessàries. ${ }^{37}$

Se trata, pues, de construir un esquema lógico-metodológico en el que queden claramente fijadas las determinaciones epistemológicas del discurso.

Estas determinaciones son el principio ontoteológico de las virtudes o atributos divinos, reconocido universalmente, bien tenga su origen en la cábala judía, ${ }^{38}$ en la doctrina agustiniana ${ }^{39}$ o en los textos islámicos; ${ }^{40}$ el principio metafísico-antropológico de las virtudes y vicios humanos y la determinación de diez condiciones, también aceptadas por las tres religiones, que garanticen el juego combinatorio de los principios. Las condiciones son: 1) La mayor perfección de las virtudes divinas y 2) la imposibilidad de su mutua contrariedad. 3) La nobleza de las virtudes humanas como signos de la nobleza de las virtudes increadas y 4) la imposibilidad de la mutua contrariedad entre ambas. 5) La discordancia entre las virtudes divinas y los vicios humanos, así como 6) la negación de la contrariedad entre ambos. 7) La negación de la contrariedad entre las virtudes humanas y 8) la afirmación de su falsedad contradictoria. Por último, 9) la discordancia entre virtudes y vicios humanos y 10) la aceptación de las virtudes más contrarias a los vicios y, viceversa, el rechazo de los vicios más contrarios a las virtudes. Estas diez condiciones se reducen, como los diez mandamientos, a dos: La concordancia con la primera finalidad y su no contradicción con ella.

\footnotetext{
35 Llull, Liber de fine, pp. 100-103.

36 Llull, Idem, p. 114.

37 Llull, «y ya que no nos podemos avenir por autoridades, ensayemos si nos es posible concordar por razones demostrativas o necesarias» Llibre de gentil, Norl., p. 12.

38 Millas, Josep M., "Las relaciones entre la doctrina luliana y la cábala» en Actes du ler Congrès Inrt. de Philosophie Médievale, Paris- Louvain (1960), pp. 435-442.

39 Llinares, Amand, «Introduction», en Llull, Ramon, L'Art bref, Paris, ed, du Cerf, 1991, pp. 46-49.

40 Asin Palacios, Miguel, «Mohidin», Homenaje a Menéndez y Pelayo, Madrid (1899), pp. 217-256.
} 
Estas condiciones, que ocupan un papel central en otras obras lulianas (Ars universalis, Liber principiorum theologiae, Liber principiorum philosophiae, Liber de Sancto Spiritu, Blanquerna, Llibre d'amic e amat) desaparecen sin embargo a partir del Llibre de meravelles. ${ }^{41}$ El método pertinente a ese esquema ontológico-epistemológico es el de la combinatoria simbólica de los cinco árboles. Por una parte, el discurso afirmativo - una especie de teología positiva - obtenido por las combinaciones binarias de las virtudes divinas (bondad, grandeza, eternidad, poder, sabiduría, amor, perfección) conforme a las reglas 1 y 2 , y de las virtudes humanas (fe, esperanza, caridad, justicia, prudencia, fortaleza, templanza), según las reglas 7 y 8 , formando respectivamente los árboles 1 y 4 , y por la combinación binaria entre las virtudes divinas y las humanas, aplicando las reglas 3 y 4 en la construcción del árbol 2. Mediante símbolos literales, como hace Llull en el Arte, los árboles 1 y 4 dibujan figuras de veintiuna combinaciones y las del árbol 2 son cuarenta y nueve:

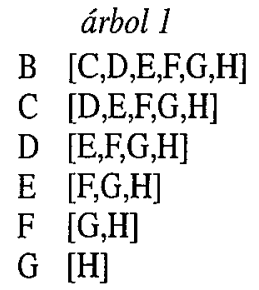

\begin{tabular}{ll} 
& \multicolumn{1}{c}{ árbol 4} \\
$\mathrm{I}$ & {$[\mathrm{K}, \mathrm{L}, \mathrm{M}, \mathrm{N}, \mathrm{O}, \mathrm{P}]$} \\
$\mathrm{K}$ & {$[\mathrm{L}, \mathrm{M}, \mathrm{N}, \mathrm{O}, \mathrm{P}]$} \\
$\mathrm{L}$ & {$[\mathrm{M}, \mathrm{N}, \mathrm{O}, \mathrm{P}]$} \\
$\mathrm{M}$ & {$[\mathrm{N}, \mathrm{O}, \mathrm{P}]$} \\
$\mathrm{N}$ & {$[\mathrm{O}, \mathrm{P}]$} \\
$\mathrm{O}$ & {$[\mathrm{P}]$}
\end{tabular}

árbol 2

F [I,K.L,M.N.O.P]

$\mathrm{G}[\mathrm{I}, \mathrm{K}, \mathrm{L}, \mathrm{M}, \mathrm{N}, \mathrm{O}, \mathrm{P}]$

$\mathrm{H}[\mathrm{I}, \mathrm{K}, \mathrm{L}, \mathrm{M}, \mathrm{N}, \mathrm{O}, \mathrm{P}]$

$\mathrm{B}[\mathrm{I}, \mathrm{K}, \mathrm{L}, \mathrm{M}, \mathrm{N}, \mathrm{O}, \mathrm{P}]$

$\mathrm{C}[\mathrm{I}, \mathrm{K}, \mathrm{L}, \mathrm{M}, \mathrm{N}, \mathrm{O}, \mathrm{P}]$

$\mathrm{D}[\mathrm{I}, \mathrm{K}, \mathrm{L}, \mathrm{M}, \mathrm{N}, \mathrm{O}, \mathrm{P}]$

F [I,K.L,M.N.O.P]

$\mathrm{G}[\mathrm{I}, \mathrm{K}, \mathrm{L}, \mathrm{M}, \mathrm{N}, \mathrm{O}, \mathrm{P}]$

$\mathrm{H}[\mathrm{I}, \mathrm{K}, \mathrm{L}, \mathrm{M}, \mathrm{N}, \mathrm{O}, \mathrm{P}]$

Por otra parte, el discurso negativo — cierta teología negativa - formado por la combinatoria de oposición entre las virtudes divinas y los vicios (gula, lujuria, avaricia, acedia, soberbia, envidia, ira), siguiendo las condiciones o reglas 5 y 6 del árbol 3 , y entre las virtudes humanas y los vicios, aplicando las reglas 9 y 10 para la construcción del árbol 5, cuya combinatoria, siempre binaria, aportaría también cuarenta y nueve parejas respectivamente:

41 Bonner, Antoni, «Introducció» en Llull, o.c., p. XXI. y Bonner, Antoni, «La situación del Libre del gentil dentro de la enseñanza luliana en Miramar», Estudios Lulianos, XXII (1978), pp. 49-55. 
árbol 3
B $[\mathrm{Q}, \mathrm{R}, \mathrm{S}, \mathrm{T}, \mathrm{V}, \mathrm{X}, \mathrm{Y}]$
C $[\mathrm{Q}, \mathrm{R}, \mathrm{S}, \mathrm{T}, \mathrm{V}, \mathrm{X}, \mathrm{Y}]$
D $[Q, R, S, T, V, X, Y]$
E $[Q, R, S, T, V, X, Y]$
F $\quad[Q, R, S, T, V, X, Y]$
$\mathrm{G} \quad[\mathrm{Q}, \mathrm{R}, \mathrm{S}, \mathrm{T}, \mathrm{V}, \mathrm{X}, \mathrm{Y}]$
$\mathrm{H} \quad[\mathrm{Q}, \mathrm{R}, \mathrm{S}, \mathrm{T}, \mathrm{V}, \mathrm{X}, \mathrm{Y}]$

árbol 5

I $\quad[Q, R, S, T, V, X, Y]$

$\mathrm{K} \quad[\mathrm{Q}, \mathrm{R}, \mathrm{S}, \mathrm{T}, \mathrm{V}, \mathrm{X}, \mathrm{Y}]$

L $\quad[Q, R, S, T, V, X, Y]$

M $[Q, R, S, T, V, X, Y]$

$N \quad[Q, R, S, T, V, X, Y]$

O $\quad[Q, R, S, T, V, X, Y]$

P $\quad[Q, R, S, T, V, X, Y]$

La demostración de una determinada creencia religiosa no exige desarrollar toda la combinatoria, ya que sería una demostración por exceso, sino sólo las combinaciones necesarias de cada árbol para que se de una prueba suficiente. Con mucha razón, en el caso del LLibre del gentil, dado que, siendo un libro de divulgación - ffassem aquest libre als homes lecs-, se debe evitar la contraproducente pesadez del discurso.

Si per cascuna de les flors provam aquestes coses -escribe Llull-, sserà massa longa la materia; on per açò tendria en bo que per alcunes de les fflors enssercassem et provassem Deus esser, e esser en ell de les VII vertuts damunt dites, e esser resurrecció. ${ }^{42}$

El concepto de tolerancia racional no es más quer el puente epistemológico que se tiende entre la utopía de la unidad interreligiosa y la diversa realidad ideológica asentada en la multiplicidad de creencias.

Para Llull la apologética racional ha llegado a superar las dificultades de la teología de las autoridades transformado el dimittere credere pro credere en un dimittere credere pro intelligere; sin embargo no ha conseguido vencer los atavismos culturales y genealógicos. Llull afirma muy concisamente que las creencias heredadas de los antepasados y de la propia tradición cultural no pueden eliminarse por ningún método:

La ffe en la qual los avien mesos lurs pares e lurs antecesors —escribe-, que, impossibol cosa seria que hom les en pogués gitar per preicació, ni per esputació ni per nulla cosa que hom y pogués fer.

De ahí el fracaso de cualquier discurso, ya que la tradición cultural y genealógica les ata:

E per asó -sigue LLull—com hom se vol esputar ab ells e.ls vol mostrar la error en que son, encontinent, ells meynspreen tot so que hom lurs diu, e dien que en laffe en la qual lurs pares e lurs antecesors los an mesos, volen estar e murit: ${ }^{43}$

42 Si probamos estas cosas por cada una de las flores, será demasiado larga la materia; por ello vendría a bien buscáramos y probásemos por algunas de las flores que Dios es y que hay en El las siete virtudes antedichas, y que existe la resurrección. (Llull, Libre del gentil, Norl., p. 14.

43 «Es imposible poder elminar mediante la predicación y el diálogo ni por cualquier otro modo las creencias que nos han transmitido los padres y antecesores». «Por eso, cuando alguien quiere dialogar con ellos [los infieles] y desea mostrarles el error en que están, inmediatamente, menosprecian todo lo que se les dice, y contestan que quieren continuar y morir en las creencias que sus padres y antecesores les han transmitido». LLull, Llibre de gentil, Norl, p. 207. 
No corresponde al carácter global de nuestro estudio desvelar el alcance de esos condicionamientos antropológicos de la apologética racional ni si, a más de ellos, se debe contar con controles económico-políticos, que hacían oficialmente inviable el cambio de un miembro de un grupo religioso a otro. ${ }^{44}$ Sin duda, lo que en 1242 sólo sería un gesto de benevolencia de Jaime I de Aragón por superar esta situación, fue una obsesión en las obras lulianas posteriores al LLibre del gentil. ${ }^{45}$ Además, Llull sigue al respecto en la línea de los papas de su siglo, quienes, aun condenando rotundamente la infidelidad de los judíos, aconsejaban y ordenaban que los cristianos los tratasen con tolerancia porque llevan en sí la Ley de Dios.

Pese a esa grave dificultad Llull no desconfía de la eficacia del método ni de la posibilidad de la utopía, porque en el Llibre del gentil, una de sus obras primerizas, todavía no había sufrido ninguno de los reveses que soportará más tarde y, por tanto, su confianza, aunque cauta, es absoluta. ¿Acaso - se preguntan los tres sabios - no hemos sacado de nuestra primera conversación algún provecho? Evidentemente, sí: Ha sido posible el diálogo interreligioso; se ha encontrado un método racional común, aceptado por las tres religiones; se han abandonado los argumentos de autoridad; el gentil ha llegado a la comprensión racional del monoteísmo sin privilegiar en ningún momento alguna de las tres religiones; el judío ha confesado públicamente que, gracias al método simbólico racional de los árboles, ha cambiado algunas ideas.

¿Por qué, entonces, no seguir aplicando la apologética de la tolerancia racional recomendada por la dama Inteligencia, discurriendo per la manera dels $V$ arbres e per les $X$ condicions significades per lurs fflors. ${ }^{46}$

\section{LA TOLERANCIA RACIONAL Y EL JUDAÍSMO}

Convencido el gentil del monoteísmo y de la resurrección, advierte que existen diferencias entre los tres monoteismos y suplica a sus sabios que cada uno exponga la razón (sa raó) de su creencia. Para ello adoptan una serie de condiciones formales: El orden de preferencia de la exposición seguirá el criterio de antigüedad, por eso. el judío será el primero en hablar y sucesivamente el cristiano y el musulmán. La metodología será la de la combinatoria del árbol de la ciencia. Se respetará siempre la tolerancia de benevolencia, descartando polémicas y discusiones con el fin de evitar mala volentat en humá coratge y torbar l'enteniment a entendre. Aquella idea cartesiana, tan traída y llevada, de una razón pura, casi inmaculada, libre de los desvíos de la corrupción de las costumbres, está ya muy presente en Ramon Llull. Sólo el gentil, símbolo de esa razón alejada de creencias dogmáticas, podrá preguntar para aclarar y precisar conceptos. ¿Cabría pensar que el gentil fuera un recurso filosófico para que el autor, sin dependencias ideológicas, interpelara críticamente a cualquiera de las tres religiones? La combinatoria, como sucedió en el primer libro, no irá más allá de la extensión necesaria y suficiente para formular

\footnotetext{
44 Poliakov, o.c., pp.139-142.

45 Trías Mercant, Sebastián, «La ideología Luliana de Miramar», Actas del II Congreso Internacional de Lulismo, Palma de Mallorca (1979), vol. I, pp. 9-29.

46 Liull, Llibre del gentil, Norl., p. 209
} 
un argumento probatorio, evitando así longues paraules superflues. Cristianismo y mahometismo, además, aceptarán por válidos — ahí la confianza absoluta de LLull en la razón- los argumentos del sabio judío sobre aquellos artículos en los que los suyos no aporten nada nuevo. Assats convinentment o a provat lo jueu, dice el cristiano; a lo que asiente el gentil: Assats me tenc per pagat de la provanssa que.l jueu a feta [...], per que a tu no qual provar lo article, cor ja es provat. ${ }^{47}$

Después de las acostumbradas preces, el judío establece los artículos de su fe -existencia de un solo Dios, Dios creador de cuanto existe, manifestador de la ley de Moysés, el Mesias liberador, la resurrección, el juicio de Dios de buenos y malos, la gloria celestial y la realidad del infirno-, artículos que sucesivamente irá probando.

Se podría buscar — cosa que no hace ahora al caso- ciertas semejanzas de los artículos de fe judía en el Llibre del gentil con algunos de los principios formulados por Maimónides en el Comentario de la Mishna, ${ }^{48}$ y subrayar, a través de algunas matizaciones del texto, cual era el conocimiento de Llull respecto de la teología judía. ${ }^{49}$ Sin embargo aquí sólo interesa precisar la noción de tolerancia en función de las relaciones judeo-cristianas.

El concepto de tolerancia racional no exige la identidad ideológica entre judaísmo y cristianismo. Por este motivo Llull escribió el Liber praedicationis contra iudaeos (1305) y el De adventu Messiae. Implica simplemente la posibilidad epistemológica de tender un puente entre el discurso ideológico de ambas religiones.

Llull adopta una postura muy clara al respecto. Pretende presentar la fe cristiana como un bloque monolítico de creencias frente a las fisuras internas del judaísmo. En el caso del judaísmo, el gentil del libro luliano, no sólo saca a luz las divergencias y sectarismos internos, sino también los cambios que se producen en ellos. Pese a la creencia judía en la resurrección, Llull no sólo procura resaltar las diferencias judaicas en entenderla - la corriente de quienes, como los saduceos de la época de Cristo, la niegan; la opinión de aquellos que creen sólo en la resurrección de las almas, corriente de inspiración platónica o filónica; la tendencia de los que defienden la resurrección al fin de los tiempos, para justificar el juicio de buenos y malos--, sino también subraya el paso del judío, personaje del libro, de una secta a otra.

En aquesta (opinió) -confiesa el judío- yo era ans que vengués en aquest loc; pero después de agés lest en les fflors dels V arbres [...], en aquesta opinió -la tercera- son yo, $e$ vull esser. ${ }^{50}$

Ramon LLull para afianzar el monolitismo cristiano, antes de exponer los artículos de la fe, advierte al gentil que le será difícil comprender las razones por las cuales se le va a probar dichos

47 «El judio ya lo ha probado suficientemente», dice el cristiano; a lo que asiente el gentil: (Llull, Llibre del gentil, Norl., p., 90.)

48 Zac, S., Maimónides, París, 1965, p. 103.

49 Llinares, «ntroduction», en Lulle, o.c., pp.24-27.

50 «A esta opinión — confiesa el judio- yo también la aceptaba antes de venir a este lugar», pero, después de «haber leído en las flores de los V árboles (...), estoy en esa opinión --la tercera-, y en ella quiero seguir» (Llull, Llibre del gentil, Norl., p. 72.) 
artículos. A veces, incluso, dada esa gran dificultad puede parecer que no queda probado lo que realmente lo está. Más adelante, ante ciertas preguntas del gentil, que en cierta manera vendrían a dar razón a la observación inicial, el cristiano se queja recriminando al gentil: Tú oyes, mas no entiendes, cosa que imposibilita la comprensión de cualquier argumento fundado en las flores de los cinco árboles.

La historia, sin embargo, obligará a Llull a reconocer que también el cristianismo tiene fisuras internas y su unidad está comprometida por la disidencia cismática y por las corrientes heterodoxas. Llull llegará a afirmar en la Disputatio Petri clerici et Raymundi phantastici que tales fisuras son la causa de que la conversión de los infieles sea un fracaso. Pero, en el Llibre del gentil, el gentil volverá a situar al cristiano-Llull en el ámbito de la tolerancia racional, al exigirle, al tratar el tema de la encarnación, que diga lo que opinan al respecto judíos y musulmanes. Ante tal situación, el cristiano-Llull, en un acto de verdadera humildad, indica que nosaltres crestians son necligents a significar e a demostrar nostra creenssa als infeels, por lo que éstos tienen dificultades de comprensión y confunden el verdadero significado de nuestra creencia. ${ }^{51}$

El gentil compromete también al judío cuando, al hablar de la ley mosaica, le pregunta qué opinan los cristianos y los musulmanes. Esta vez, sin embargo, la respuesta se orienta señalando las coincidencias y las diferencias entre las tres religiones. Cristianos y musulmanes creen que Dios ha dado la ley a Moisés y que la ley judaica es, por tanto, verdadera. ${ }^{52}$ Judíos y cristianos coinciden en el la literalidad del texto, pero difieren en las glosas del mismo. Por ello, ya que no convienen por autoridades, buscan coincidir mediante razones. Los musulmanes concuerdan sólo en parte con el texto judío, circunstancia que les lleva a afirmar que los judíos han manipulado el texto de la ley, mientras éstos dicen que aquéllos tienen un texto diferente. ${ }^{53}$

Desde esta perspectiva de coincidencias y diferencias se plantea el tema del mesianismo, un tema central en las relaciones entre cristianos y judíos. Recordemos las disputas de Barcelona y de Tortosa sobre el caso. En ambas religiones encuentra Llull una categoría de concordancia. Tal es el concepto de «esperanza» ${ }^{54}$ Pese a la coincidencia, el significado es distinto en unos y otros.

En el judaísmo la esperanza mesiánica, al comparar poder y esperanza en el árbol 2, tiene el sentido socioantropológico de «espera». Creer que se hará realidad la venida de un mesías liberador; un enviado por el poder de Dios con poder suficiente para destruir el orgullo del pueblo cristiano y musulmán, causa del cautiverio judío y, como consecuencia, para librar al pueblo judío de la esclavitud. El argumento luliano es éste:

«Tot lo poble dels jueus a esperanssa que per la vertut e.l poder de 1 home, so es Messies, sia vensut e sobrat tot lo pòder dels homes d'aquest mon [...]. Lo poder de Deu es tan gran, que dará a aquell home, so es Mecies, tan gran poder, e a ordenar que nosaltres ajam gran

51 Llull, Llibre del gentil, Norl, p. 131.

52 Efectivamente, Cristo no abolió la ley antigua (Mateo, 5, 127) ni Mahoma tampoco (Corán, II, 40, 83-84; $\mathrm{V}, 12-13)$

53 Liul, Llibre del gentil, Norl., p. 65. Sin embargo, un texto del Corán (II, 83) sobre la alianza con los hijos de Israel es un remedo del Exodo (20,3, 12-13) y del Deutoronomio $(5,7,16-17)$.

54 Llull, Llibre del gentil, Norl., pag. 147 y 68. 
esperanssa en so que per l'home ajam esperanssa a esser exits de la servitut en que som [...]. E per asó prova's que Mesies deu venir per nos a delirar». ${ }^{55}$

Para el cristianismo, en cambio, la esperanza comporta un significado metafísico-teológico de «recreación» de la naturaleza humana caída por el Cristo, mesías Hombre-Dios. Tal significado resulta de la combinación del amor y la caridad en el árbol 2 de las virtudes divinas y humanas y de la esperanza y la avaricia del árbol 5 de la oposición de las virtudes humanas y los vicios. La recreación o restauración de la naturaleza humana al estado de gracia destruido por el pecado de Adán no es privilegio de un pueblo sino una gracia para toda criatura, cuyo cumplimiento no es posible - escribe Llull-:

sens que natura humana no fos una persona ab inffinida bonea, granea, etc., per la qual persona la natura nostra fou recreada, per tal que retornás concordanssa esser enfie nos $e$ la final raó a la qual som creats. 56

Concluye Llull su argumento, remitiendo al gentil a las pruebas que se derivan de los árboles pertinentes:

Con en la natura humana de Jesu Crist e en la sua passió e mort, Deus demostra la perffecció de les fflors del primer arbre e del segon e del quart. ${ }^{57}$

Sebastià Trías Mercant

Plaza de Barcelona, 20, 6. ${ }^{\mathrm{a}}$, 2. $^{\mathrm{a}}$ 07011 Palma de Mallorca (Baleares)

55 «Todo el pueblo judío tiene esperanza que por la virtud y el poder de un solo hombre, es decir el Mesías, sea vencido y superado todo el poder de los hombres de este mundo [...]. El poder de Dios es tan grande, que dará a aquel hombre, es decir al Mesías, tan gran poder, y ordenar que nosotros tengamos gran esperanza en lo que por un solo hombre esperamos a ser sacados de la esclavitud en la que estamos [...]. Por ello se prueba que el Mesías debe venir a liberarnos». LLull, Llibre de gentil, Norl., p. 68.

56 «Sin que la naturaleza humana no fuera una persona con infinita bondad, grandeza, etc., por cuya persona nuestra naturaleza fue creada, para que se concordara de nuevo entre nosotros y la razón última de nuestra creación». Llull, Llibre del gentil, Norl., p. 141.

57 Llull, Llibre del gentil, Norl., p. 143. 